\title{
A model of the structure and dynamics of benthic marine invertebrate communities
}

\author{
R. G. Hughes \\ Department of Zoology, Westfield College, University of London, London, NW3 7ST, England
}

\begin{abstract}
The species abundance distributions of many benthic marine invertebrate communities may not satisfactorily conform to either the log-normal or log-series models that are central to theories of community structure. Benthic communities usually have dominance-diversity curves that are concave, rather than linear (log-series) or sinusoidal (log-normal), with a progressive increase in the number of rare species; singleton species outnumber doubletons and so on. There is no mode in the species abundance distributions. An alternative theory is presented here to offer an explanation for these observed species abundance distributions. The theory is explained by use of a model of benthic marine community dynamics based upon established principles of population regulation, notably recruitment behaviour, competition and mortality. The model simulates several previously recognised features of community development. A 'non-interactive' stage of colonisation is followed by an 'interactive' stage where, because of competitive interactions, environmental stability leads to an increase in dominance which depresses the diversity of the community and the number of species. Intermediate levels of disturbance maintain an increased diversity and a larger number of species by ensuring that dominance by any one species is only temporary and a stable 'climax' is never reached. The model consistently predicts the products of the interactions between population growth, competition and mortality to be communitites with dominance-diversity curves similar in shape to those of natural communities. The model also suggests that while many species have the potential for geometric population growth some species do not achieve this because of mortality and competitive exclusion and, within an area of study, some species may have only an arithmetic potential for population growth.
\end{abstract}

\section{INTRODUCTION}

Ecologists have for many years been intrigued by the observation that animal communities usually contain a large number of rare species, but are dominated by only a small number of abundant species. Explanations for the relative abundance of species have centred on 2 mathematical distributions, the log-normal and the log-series (Fig. 1) because the structure of most communities approximates to one or the other (reviews: May, 1975, 1981; Pielou, 1975). A log-normal distribution of species abundance is statistically expected if the resource allocation of each species is reflected by the size of its population and is influenced by several independant variables. The logarithmic scale is used because the responses of populations to environmental changes tend to be geometric rather than arithmetic. The distribution is usually truncated (as in Fig. $1 \mathrm{~A}$ ) because, it is suggested, samples are usually too small to include all the rarer species (Preston, 1948). A truncated form of the log-normal distribution is said to fit a wide variety of communities that are stable and contain a large number of species. The dominance-diversity curves of truncated log-normal communities are characteristically sigmoid because of the relatively small number of abundant and rare species (Fig. 1 B). However, in many communities there is no mode in the species abundance distribution for there are more singleton species than species in the second octave while these, in turn, outnumber species in the third octave and so on. Preston (1948) considered that the absence of a mode simply reflected a small collection from a log-normal community. However, such communities may statistically fit a log-series distribution in which the number of species with $n$ individuals is given by $\alpha x^{n} / n$ where $x=a$ constant less than 1.0 ; $\alpha=$ a constant often used as an index of diversity. The dominance-diversity plot of the log-series is mostly linear with a progressive increase in the number of rare species (Fig. 1 B). May (1975) suggested a variation of the niche pre-emption hypothesis to account for a log-series distribution. If species are recruited at 
random time intervals into a community governed by one dominant resource and the most successful species pre-empts a fraction of that resource and the next abundant the same fraction of the remainder, and so on, a log-series may be expected. The log-series is less frequently encountered than the log-normal and is thought to be applicable to small, stressed or unstable communities and to those in early successional stages.

There are 2 problems associated with describing a community as having either a log-normal or a logseries distribution. Firstly, either distribution may result from chance effects (Boswell and Patil, 1971) or sampling procedures. Combining separate samples
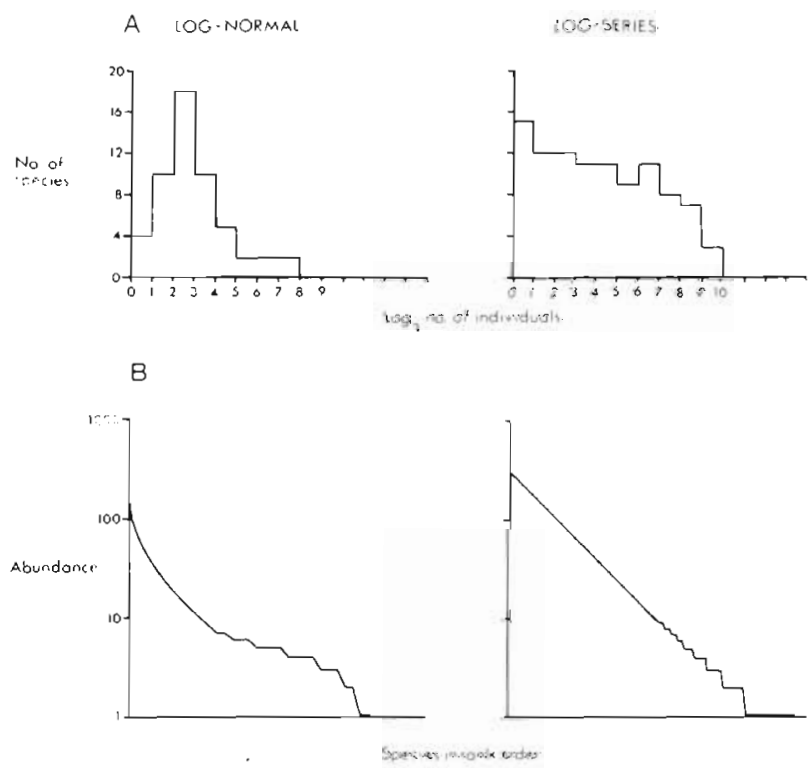

Fig. 1 (A) Species abundance distributions (expressed on a $\log _{2}$ scale) of species in a hypothetical log-normal and predicted (Fig. 3a) log-series community. (B) Dominance-diversity curves for these communities. The abundance of each species is plotted (on a log scale) in descending rank sequence

may produce a log-normal distribution even if the individual samples are log-series (Routledge, 1980; Shaw et al., 1983) while a small sample from a lognormal community may produce a distribution resembling a log-series (Routledge, 1980). Secondly, the 2 distributions may be similar over much of their range, differing only in the relative abundance of their commonest and rarest species (Kempton and Taylor, 1976; Gray, 1978). This, together with the poor differentiating qualities of the 'goodness of fit' tests usually used ('Taylor et al., 1976; Engen, 1979; Routledge, 1980 ), means that a community may statistically conform to both (Gray, 1978). This creates a dilemma over which of the 2 resource-apportioning theories may be applicable.

\section{OBSERVATIONS}

The distributions of species abundance in a selection of benthic marine invertebrate communities, from a variety of habitats and geographical areas, are presented in Fig. 2. The dominance-diversity curves of these communities are shown in Fig. 3. The majority of these and other communities (e.g. Eagle and Hardiman, 1977; Fedra, 1977; Davis and Spies, 1980; Ayling, 1981) are not satisfactorily described by either the lognormal or the log-series distribution. The exception here is the truncated log-normal of Fig. $2 \mathrm{~g}$ and $3 \mathrm{~g}$. These dominance-diversity curves are deeply concave rather than linear (log-series) or sigmoidal (log-normal). The abundant species are more numerous than in
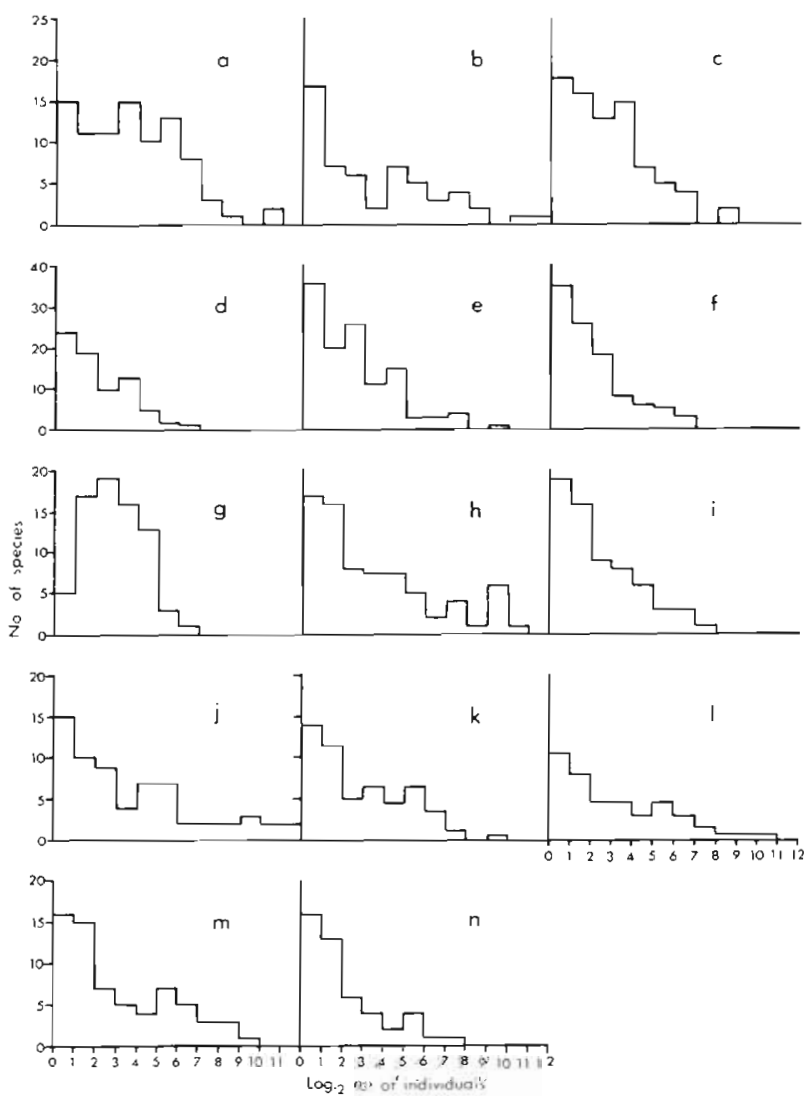

Fig. 2. Species abundance distributions of marine invertebrates in epifaunal $(a-f)$ and infaunal $(g-n)$ communities. (a) Laminaria holdfast epifauna, Suffolk; (b) intertidal algae epifauna, Suffolk; (c) sublittoral hydroid epifauna, Devon (all own unpubl. data); (d and e) Laminaria holdfast epifauna, Flamborough and St. Mary's Is., respectively (Moore, 1973); (f) coral epifauna, Great Barrier Reef (Austin et al., 1980); (g to i) benthos of Scottish sea lochs, Station 2 (1963) (Pearson, 1975). Station E-24 (Gage, 1972) and Station FL-1 (Gage, 1972), respectively; ( $j$ to 1 ) benthos off the Swedish west coast, Station L9 (Rosenberg, 1974), $100 \mathrm{~m}$ and $300 \mathrm{~m}$ (both Josefson, 1981), respectively; $(m)$ benthos off Northumberland (Buchanan and Warwick, 1975); (n) benthos off Cornwall (Probert, 1981) 

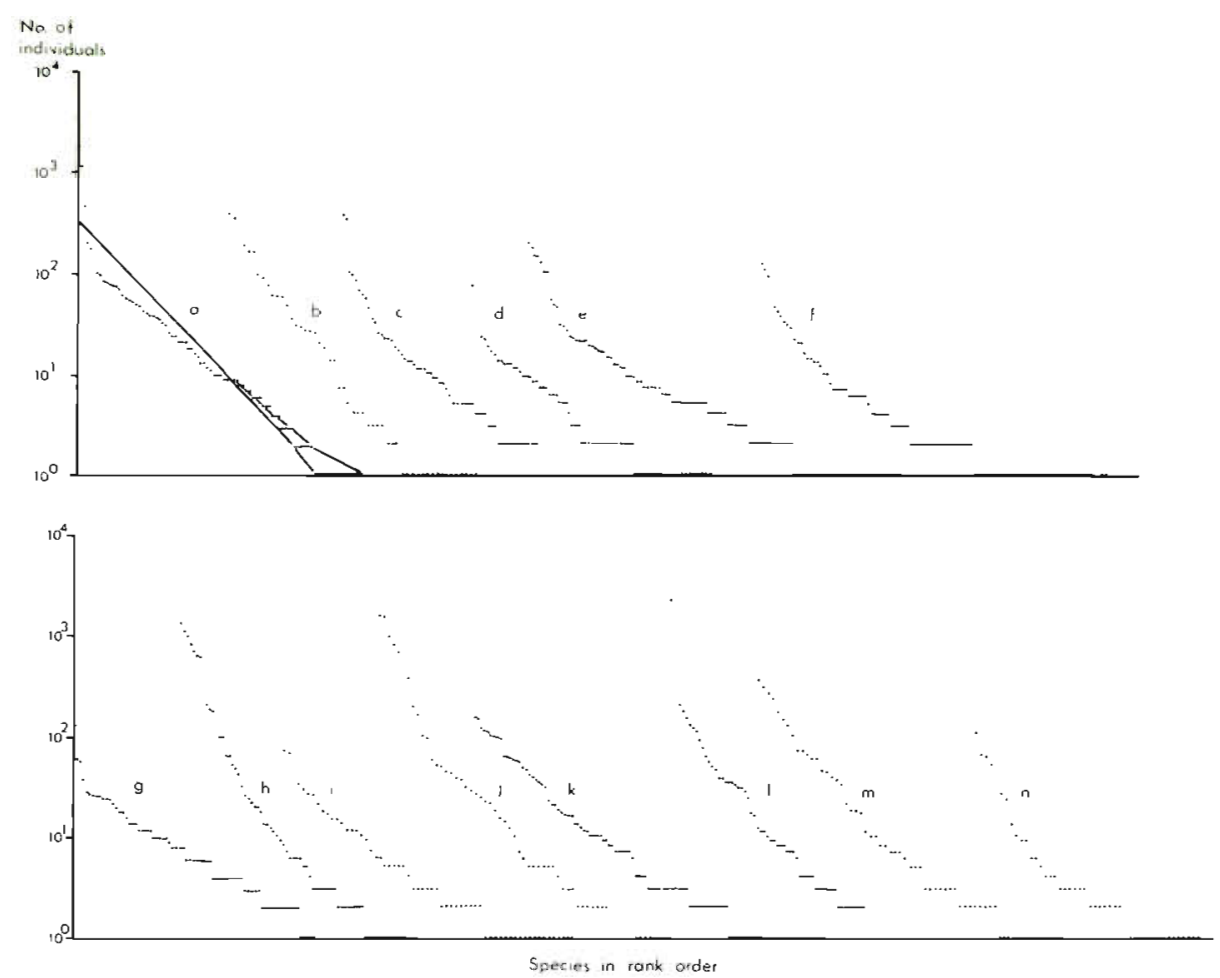

Fig. 3. Dominance-diversity curves for the communities listed in Fig. 2. The predicted log-series distribution for the Suffolk Laminaria holdfast fauna (a) (calculated as in Taylor et. al., 1976) is shown for comparison

a $\log$-series while there are too many rare species (and consequently no modal octave) to indicate a truncated log-normal. (The argument that the absence of a mode is simply the product of small samples from log-normal communities is discussed below.) The consistent deviation from these logarithmic distributions, together with the uncertainty over their application, would suggest that the resource-apportioning theories associated with these models do not offer a satisfactory explanation for the structure of benthic marine communities. In addition, several authors have expressed disquiet over the biological realism of these theories which are based more on mathematical distributions which may fit observed patterns rather than on recognised ecological principles (Pielou, 1975; Routledge, 1980; Ugland and Gray, 1982).

What then may determine these patterns of species abundance? While theoretical ecologists refer to resource-apportioning models, marine zoologists often explain differences in species abundance in terms of variations in recruitment and mortality rates, both of which may be unpredictable and influenced by historical factors (Sutherland, 1974; Osman, 1977; Sutherland and Karlson, 1977; Ayling, 1981). A theory is presented here, as an alternative to the resource-aportioning theories, to offer an explanation for the observed distribution of species abundance. The theory is explained by use of a model based upon established principles of population and community dynamics of marine benthic invertebrates, notably recruitment behaviour, mortality and competitive interactions. While these principles are generally recognised there are no data to use in the model, neither are there likely to be because of the enormity of the task which would only produce data relevant to one community at one time. However, as concave dominance-diversity curves are prevalent, even though the factors governing species abundance vary in importance from one community to another, models that seek to predict such community structure ought not depend upon specific measured parameters but should be founded on features that may be common to various marine communities, while being sufficiently robust so that the predictions do not vary significantly with different parameter values. To illustrate the properties of the model, arbitrarily selected parameters of recruitment and mortality are used. The model generates and, by reiteration, maintains a theoretical community of many species, each with their own combination of recruitment and mortality parameters.

\section{THE MODEL}

Consider a habitat consisting of 100,000 'spaces each of which may be occupied by only one species 
(either as a separate individual or by growth from an adjacent space) which inhibits invasion by other individuals except those of a competitively superior species. In marine benthic communities space is often the most limiting resource and competitive interactions (exclusion and interference) are significant processes influencing their structure and dynamics (Dayton, 1971; Jackson, 1977; Osman, 1977; Sutherland and Karlson, 1977). The number of individuals (more correctly, spaces occupied) of the $i^{\text {th }}$ species that would be present at time $t+1\left(n_{t+1}^{i}\right)$ depends upon (a) the number present at $t\left(n^{2}\right)$, (b) the number recruited $\left(r^{i}\right)$ (immigrants and births) from $t$ to $t+1$, and (c) the proportion of both of these groups that survive and do not emigrate $\left(s^{j}\right)$. Expressing this relationship as

$$
n_{t+1}^{i}=s^{i}\left(n_{t}^{1}+r^{i}\right)
$$

gives the recruits a survivorship rate of half that of the established individuals, assuming that their mean arrival time is mid-way between $t$ and $t+1$. This is the basis of the model and what follows is an expansion of the parameters of survivorship (s) and recruitment ( $r$ ).

\section{Survivorship}

Predation, disease, senescence and the occasional catastrophe that seems to affect most benthic communities have been identified as important sources of mortality of marine invertebrates (e.g. Dayton, 1971; Jackson, 1977; Osman, 1977; Sutherland and Karlson, 1977; Lubchenco and Menge, 1978; Moran, 1980; Russ, 1980; Ayling, 1981). In addition, these and other authors have stressed the importance of competition for space which may result in the death of competitively inferior individuals. Large or colonial animals may undermine or overgrow inferior competitors but the monopoly of the substratum by such dominant species is usually temporary because of their death.

Mortality is incorporated into the model in 3 ways. Firstly, the interspecific differences in survivorship from $t$ to $t+1$ from all sources of mortality, including the two specified below, are included as a normally distributed parameter $S$. In this theoretical community $S$ for each species is either $0.1,0.3_{1}, 0.3_{2}, 0.5_{1}, 0.5_{2}, 0.5_{3}$, $0.7_{1}, 0.7_{2}$ or 0.9 . Secondly, to account for the mortality associated with periodic catastrophe $S$ is multiplied by $C$ (where $C<1$ ). There are many ways in which catastrophe may be modelled but in this theoretical example $C$ is a random number between 0 and 1.0 with the proviso that if $C$ exceeded $0.3, C=1$. Thus, each species has an equal chance $(30 \%)$ of suffering a catastrophic mortality from $t$ to $t+1$ where its population will be reduced by between $70 \%$ and $100 \%$. The figure of 0.3 was chosen as it gives a good illustration of the influence of both stability and perturbation on the community. An equal risk of catastrophic mortality may be true for species on unstable habitats, such as boulders that occasionally overturn (Osman, 1977), but it would not be true if a species is particularly at risk, for example large animals are more likely to be dislodged by rough seas. However, the interspecific variation in this risk is already incorporated under $\mathrm{S}$. Thirdly, the risk of mortality from competitive interference is likely to increase with an increase in community density for all but a few competitively superior species. This relationship is totally unpredictable as it varies with the species composition of the community but there will be interspecific variation in this risk and this is also incorporated under $\mathrm{S}$. For the purposes of calculation for this theoretical community it was arbitrarily decided that the mortality risk should increase cubically with increasing community size $\left(N_{v}\right)$ so that survivorship decreased by $5 \%$ at $N_{t}=60,000$ and by $20 \%$ at $N_{t}=100,000$. This was achieved by dividing $S$ by $1+Q$ where

$$
\mathrm{Q}=\frac{\left(\mathrm{N}_{\mathrm{t}} \times 10^{-3}\right)^{3}}{4 \times 10^{6}}
$$

The survivorship component of Equation (1) now reads

$$
s^{i}=\frac{S^{i} \times C}{1+Q}
$$

and produces a survivorship level for each species that fluctuates (because of $Q$ ) around a specific level (determined by $S$ ) but with an occasional catastrophic decline (because of $C$ ).

\section{Recruitment}

The rate of colonisation of a substratum by a species depends upon, (a) recruitment potential, i.e. the number of invasive individuals that reach the substratum, (b) the availability of space, and (c) whether these individuals occupy the space or continue dispersing. Recruitment potential largely depends upon the number of dispersing individuals despatched from the parent population and the proportion of these that reach the substratum; the latter being influenced by their mortality rate, the time spent dispersing and direction and strength of currents. Interspecific variations in recruitment potential are included in the model as a variable parameter $R$. In this theoretical community each species is given one of the 10 values from 1 to 10 .

Although recruitment potential also varies with time, usually seasonally, the actual recruitment into established communities may reflect more the availability of space resulting from the mortality of previous 
colonists for, although small amounts of space may be regularly available, intermittent larger scale mortality that releases large areas is a significant feature of many communities (Jackson, 1977; Osman, 1977; Sutherland and Karlson, 1977; Karlson, 1978; Lubchenco and Menge, 1978; Ayling, 1981). The single value of $\mathrm{R}$ for each species predicts a constant hierarchy of immigrant species but the species that colonise new space will be those that happen to be dispersing when it becomes available. A further source of uncertainty is that recruitment may also reflect the ability of dispersing individuals to displace established animals, for competitively superior species have, in effect, more space available to them. The degree of advantage to any immigrant is unpredictable as it also depends on the competitive status of the resident it is trying to displace. To simulate the temporal fluctuations in the species composition of immigrants, and the unpredictable intensity of their settlement, $\mathrm{R}$ is multiplied by $V$. In this example $V$ is a random number between 0 and 1.0 and is used to temporarily raise or lower the position of a species in the hierarchy of recruits so that, for example, species with a low overall recruitment potential will occasionally have a higher recruitment than species with higher $R$ values.

In addition to variations in recruitment potential the intensity of colonisation of most benthic species is often related to the number of established conspecifics, for 1 of 2 main reasons.

(1) Most marine invertebrates disperse as larvae which are usually highly selective in their choice of settlement site and commonly settle in response to the presence of (a) conspecifics or (b) other specific stimuli, other species or the physical or chemical characteristics of the habitat (Meadows and Campbell, 1972; Crisp, 1976). The presence of conspecifics may therefore (a) confer or (b) reflect the attractiveness of the substratum. If, for the moment, it is assumed that the recruitment potential of each species is constant and that the habitat has an unlimited capacity, the intensity of future settlement may be directly proportional to the density of established conspecifics $\left(n_{\nu}^{i}\right)$. However, neither of these 2 conditions are realistic but temporal variations in recruitment potential have already been included in the model and the constraints associated with the availability of space are incorporated later.

(2) Species with no larval stage generally brood their young which usually disperse only short distances and may delay dispersal until later in their lives (Hughes, 1979). Here the number of recruits (births) will also be proportional to the size of the established (parent) population. After dispersal individuals of these species may also show selectivity of the kind previously associated with larvae (Campbell and Meadows, 1974; Stoner, 1980).
Given an interspecific variation in the relationship between established conspecifics and recruitment, the recruitment of each species from $t$ to $t+1$ may be expressed as $\mathrm{r}^{\mathrm{i}}=\mathrm{V} \times \mathrm{R}^{\mathrm{i}}\left(1+\mathrm{Z}^{\mathrm{i}} \mathrm{n}_{\mathrm{t}}^{\mathrm{i}}\right)$

where $Z=$ an index of the enhancement of immigration conferred or reflected by each established conspecific. Looking at this from a distributional viewpoint, most marine invertebrates have contagious dispersions, largely as a result of (1) and (2) above, in which the presence of one individual statistically (as well as biologicallyl increases the liklihood that another will occur close by, and here $Z$ may be regarded as a statistical index of aggregation. $Z$ will vary interspecifically as it reflects differences in the behaviour of each species, being high in gregarious species that have highly aggregated distributions and low, or zero, in species that have wide substrate preferences or hold territories and separate themselves from conspecifics. Each species in this theoretical community has one of the six values from 0 to 0.5 inclusive. If the population of a territorial species reaches a high density, intraspecific exclusion could produce a negative value for $Z^{2}$ (whereupon $r^{i}$ tends to 0 ) but for simplicity these constraints on immigration are incorporated together with those associated with interspecific exclusion.

As this community develops and $N_{t}$ increases toward $10^{5}$, the potential for further recruitment is proportionately reduced and the recruitment component more realistically represented with an asymptotic correction

$$
I^{i}=V \times R^{1}\left(1+Z^{1} n_{t}^{i}\right) \frac{\left(10^{5}-N_{t}\right)}{10^{5}}
$$

However, a refinement to this correction was thought desirable following preliminary trials with the model. At low community densities, when recruitment exceeds mortality, the amount of recruitment that may occur from $t$ to $t+1$ is overestimated, for as immigration proceeds during this period progressively fewer than $10^{5}-N_{i}$ spaces are available. Conversely, at high densities, when mortality exceeds recruitment, more than $10^{5}-N_{t}$ spaces are available and recruitment is underestimated. The levels of recruitment and mortality from $t$ to $t+1$ are explicitly unpredictable but in an effort to reduce immigration at low densities and to increase it at high densities $N_{t}$ in the above expression was multiplied by $E$, calculated as described in the Appendix. In the absence of $E, N_{t+1}$ often exceeded 100,000 because of excessively high recruitment when $N_{t}$ was low, whereas its inclusion dampened such increases so that this carrying capacity was never reached. The final version of the model is

$n_{1+1}^{1}=\frac{S^{i} \times C}{1+Q}\left(n_{t}^{i}+V \times R^{1}\left(1+Z^{i} n_{t}^{1}\right) \frac{\left(10^{5}-N_{t} \times E\right)}{10^{5}}\right)$ 

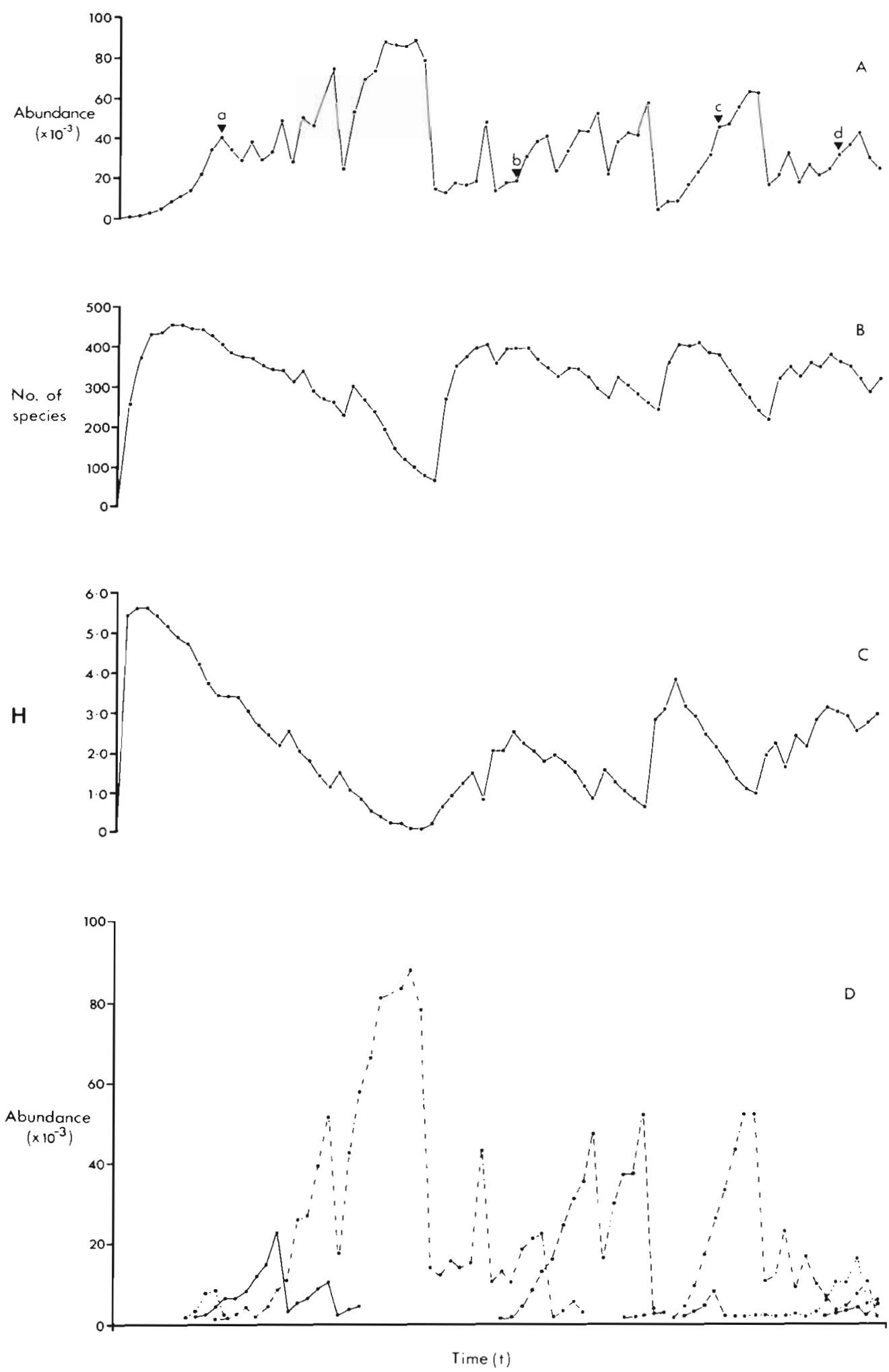

Fig. 4. Development of the theoretical community generated from running the model from $t=1$ to $t=75$. (A) Total number of individuals; (B) number of species; (C) diversity of the community expressed as ' $H$ ', Shannon-Wiener index; (D) sizes of the populations of the 5 species that at some time dominated the community; * * species with ' $\mathrm{S}=9, \mathrm{R}=9, \mathrm{Z}=5$ '.

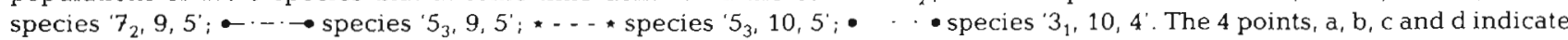
the stages where data for Fig. 5 were abstracted 
which produces a 'community' with a variable number of species. Here the maximum is 540 , one for each combination of $S, R$ and $Z$.

\section{RESULTS AND DISCUSSION}

\section{Community dynamics}

The results gained from running the model from $t=0$ (introduction of the substratum) until $t=75$, with the previously nominated values for the parameters are summarised in Fig. 4. Only the integer value for the abundance of each species was used and therefore the species whose abundance was less than 1.0 were considered to be absent. Initially the number of colonising species is high, as is the diversity of the community and this period would seem to correspond to the 'non-interactive' stage of colonisation of islands described by Simberloff and Wilson (1969). As the density of the community increases the 'interactive' stage is reached where many of the competitively inferior opportunist species (those with high recruitment but low survivorship) are gradually displaced by the small number of species that become abundant and both the community diversity and the number of species declines. Given reasonable stability the dominance of the community by these few species would increase and the diversity continue to decline but when an abundant species suffers a high mortality and the community density falls, the newly available space is colonised (by an unpredictable suite of species), whereupon both the number of species and the diversity of the community increases. In this theoretical community, as in natural communities (Osman, 1977; Connell, 1978; Ayling, 1981), intermediate levels of perturbation help to increase diversity and maintain a dynamic equilibrium of species number. This is also true of the model as a whole where both relative stability (e.g. $C=0.1$ ) and extreme perturbation produce communities with diversities lower than in this example.

In communities with a smaller species pool than in this example, and with a smaller number of species recruiting at the same time, the early stages of colonisation may be more predictable, particularly if there are a small number of opportunist species with a high recruitment potential that is maintained for most of the year. Here the early colonisation will be characterised by a slower rise in species number and community diversity in a longer, and perhaps less obvious, "noninteractive' stage. For example, the opportunistic polychaetes Capitella and Polydora regularly dominate young communities of marine sediments (Gray, 1981) which consequently have a low diversity. How- ever, as these communities develop and accumulate more species their dynamics more closely resemble the essential features illustrated by this model.

There has been much recent discussion over whether marine communities exhibit succession and develop in a predictable sequence toward a climax state or one of several 'polyclimax' states (Osman, 1977; Sutherland and Karlson, 1977; Keen and Neill, 1980; Ayling, 1981). In this theoretical community the sequence of colonisation and the hierarchy of immigrants are unpredictable as is the incidence of mortality. Development of the community in periods of stability proceeds unpredictably from a variable stock and any one of many species may temporarily dominate (Fig. $4 \mathrm{D}$ ). The fluctuations in the populations of the most abundant species (Fig. 4 D) illustrate the continual interchanging of rank that occurs at all levels in the hierarchy as the population of each species rises or falls. Species ' 9 , 10, 5 ' never became abundant, despite having the highest values for the three parameters, because initially its recruitment was low (because of low $V$ and subsequent growth of the population, already slow because $n_{\mathrm{t}}^{1}$ was small, was suppressed by competitive exclusion and catastrophic mortality. In contrast, species ' 3 , 10,4' happened to have a high recruitment from $t=64$ to 70 and despite its low value of $S$ was able to dominate the community briefly by occupying space vacated by the catastrophic mortality of species ' $53,9,5$ ' (Fig. 4 D). Thus, in this model perturbations interupt community development so that dominance is only temporary, as well as unpredictable, and a stable climax is never reached. This is a feature of marine communities which Gray (1981) illustrated by reference to the concept of neighbourhood stability, where there are many 'locally stable points' each representing a particular hierarchy of species, and which vary in their resistance to disturbance.

\section{Community structure}

The dominance-diversity curves of this community at 4 points in its history ( $a, b, c$, and $d$ in Fig. 4 A) are shown in Fig. 5. The model predicts concave dominance-diversity curves, similar in shape to those of natural marine communities (Fig. 3), with a rapid decline from a small number of abundant species to a progressively increasing number of rarer species. Other ranges of values for $R, S, Z$ and $C$ have also been used in other trials with the model and produce communities with dominance-diversity curves of different dimensions but curves of this shape is a robust prediction of this model.

The dominance-diversity plot is this shape for the following reasons. The potential population growth for 


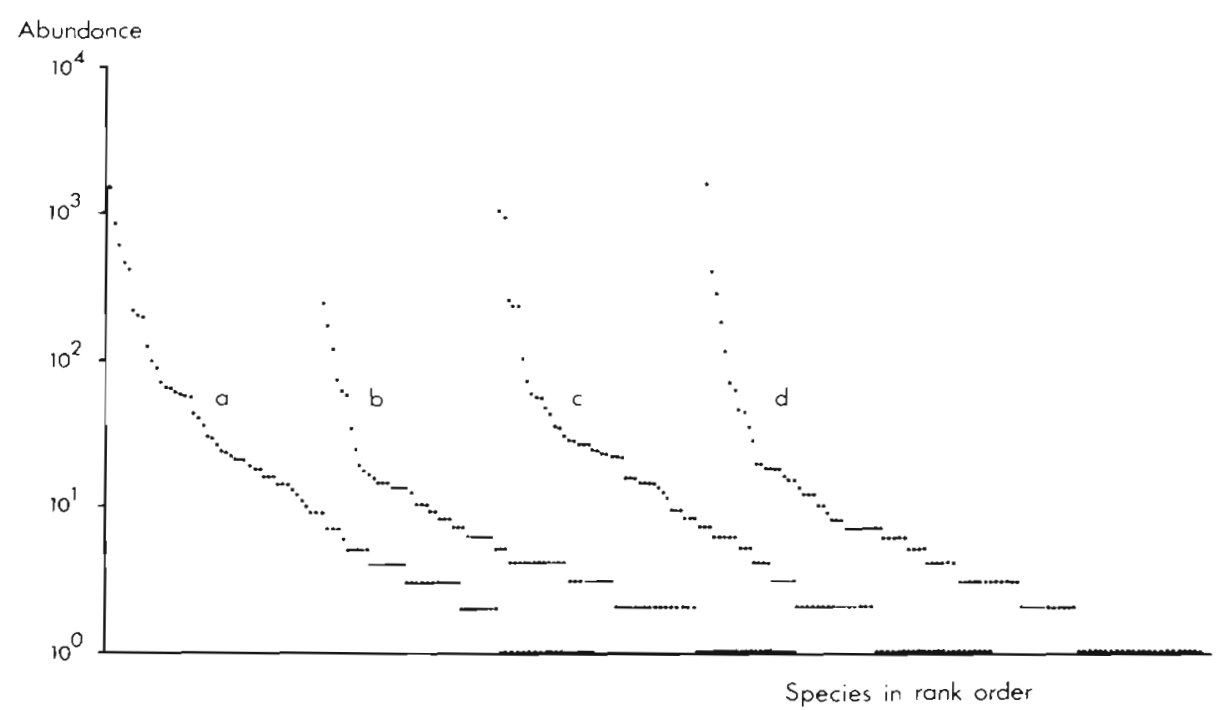

Fig. 5. Dominance-diversity curves for a 'sub-community' of 100 species chosen randomly from the theoretical community at the 4 points (a-d) indicated in Fig. 4

species with $Z=0$ is arithmetic but for the other species, whose recruitment is related to their abundance, the early stages of population growth are potentially geometric, as in the logistic growth curve. As the values for the survivorship and/or recruitment parameters decline through the species spectrum, the species have progressively lower geometric growth potential with increasingly longer initial ('flat') stages where population growth is slow. These species require a progressively longer time to reach the population sizes needed to generate rapid recruitment, via $\left(1+Z n_{t}^{i}\right)$, particularly if $Z$ is small. However, the occasional interruption to the growth of each population, and the repression of recruitment associated with competition with superior species, means that these species have a progressively smaller chance of reaching the population sizes necessary to generate rapid recruitment. Consequently, only a few species achieve rapid population growth, and these do so only briefly (Fig. 4 D), because their expanding populations repress further recruitment into the community. As the abundance of the most numerous species are the result of different geometric growth rates the differences between the population sizes of adjacent ranking species are larger than if their abundance were in the same geometric series. Therefore, dominance is greater than that predicted by the log-series, a statistical variant of the geometric series (May, 1975). The concave curvature of the dominance-diversity plot reflects the progressive decline in significance of geometric population growth, which gradually reduces the differences in abundance of adjacent species lower in the hierarchy.

This association between variable geometric potential growth and concave dominance diversity curves is illustrated by Fig. $6 \mathrm{~A}$ which summarises the principal features of community development simulated by this model. In this illustration the community has 150 species each with a unique geometric potential for growth. (While the model provides for species with arithmethic growth only a small number of these appear in the resulting community and, for now, arithmetic growth is ignored.) Because of the fluctuations in $V$ each species has a potential growth zone, rather than a curve, bounded by a maximum level ( $V$ always $=10$ ) and a minimum level ( $V$ always $=0$ ) at which the species is absent. The maximum level is a geometric curve whose slope is determined by $R, S$ and $Z$ which are constant for each species. In Fig. $6 \mathrm{~A}$ the maximum potential growth curves of every tenth species are shown and presented as straight lines on a logarithmic scale. The short length of the horizontal axis, which determines the maximum possible abundance, is consistent with the model which suggests that geometric growth is only achieved for short periods. Each species moves within its growth zone (i.e. from its maximum to below the horizontal axis) according to variations in recruitment (due to $V$ and the asymptotic correction) and mortality (due to $C$ ). If this movement is independent of the abundance of any other species (but not of the total community) each species has a greater probability of having $n$ individuals than $n+1$, in proportion to the ratio of the areas under the line occupied by these respective integers. This area declines with increasing abundance for two reasons: because of the slope of the line and because higher abundance values occupy a progressively smaller length of vertical axis. A dominance-diversity curve drawn from a randomly selected point in each of the 150 growth zones will, 

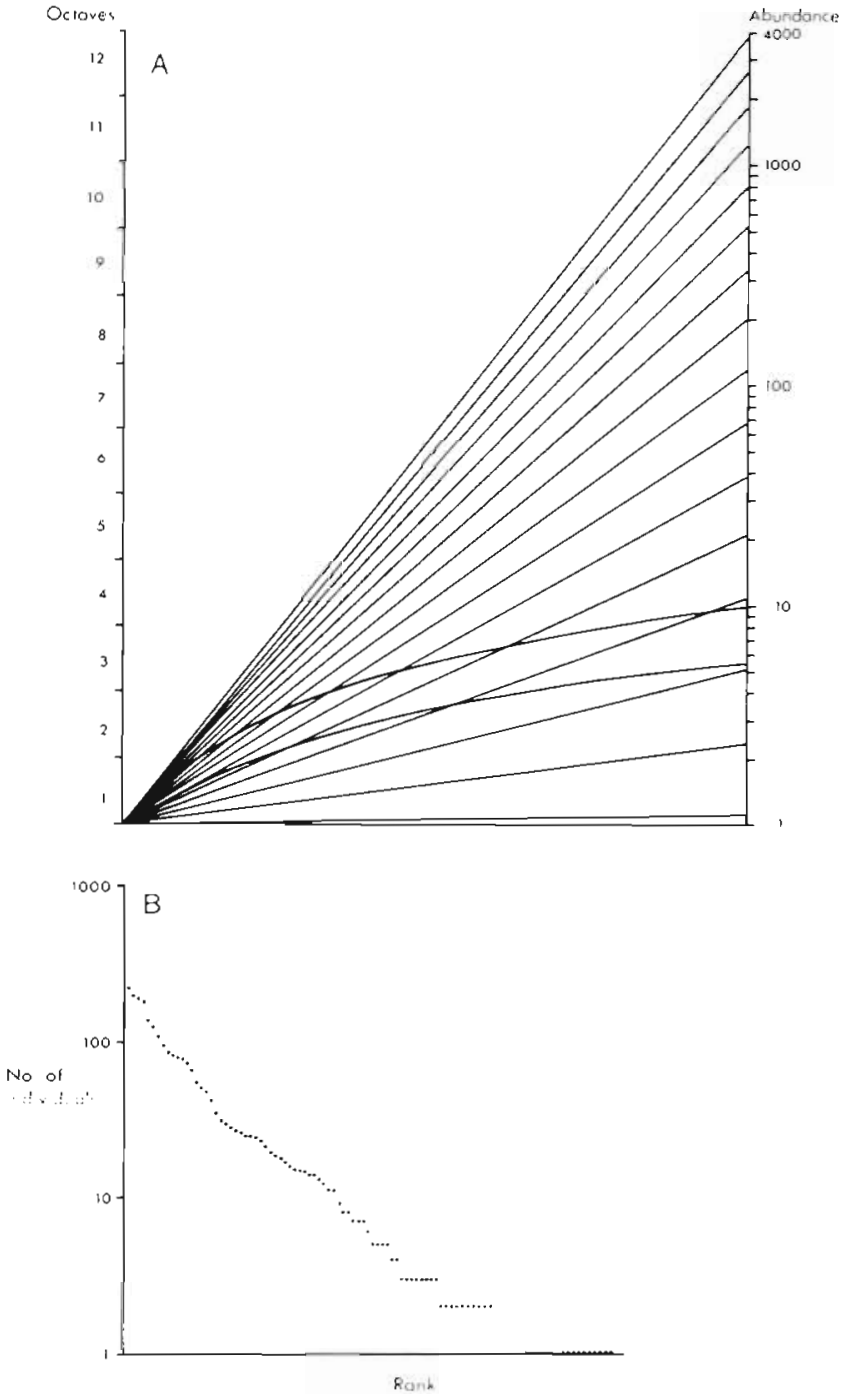

Fig. 6. (A) The maximum growth potentials of 150 species, each with a unique geometric potential growth rate, were simulated by calculating $x^{y}$ for 150 values of $x$ from 1.0 to 2.5 and $y$ from 1 to 9 . ( $y$ is no larger for reasons described in the text.) Here the maximum attainable abundance for every tenth species is shown. Two arithmetic growth curves are shown for illustration, the upper curve representing the addition of 1 individual for each $y$ value and the lower $1 / 2$ this rate of increase. (B) Dominance-diversity curve drawn from points selected randomly from each of the 150 growth zones

therefore, be a concave curve with more singleton species than doubletons and so on (Fig. 6 B). Similarly, a few more species may be expected to occur in the $n^{\text {th }}$ octave than in the $n+1^{\text {th }}$, because higher octaves have progressively smaller areas under each curve. Therefore no mode in the species abundance distribution is predicted. The abundance of one species can affect the abundance of others when environmental stability allows it to dominate the community, whereupon the consequent decline in recruitment will tend to move the inferior species lower in their respective growth zones. This model suggests that under stable conditions competitive exclusion increases in importance and a greater proportion of the constituent species appear in the lower octaves.

The explanation for the log-normal distribution is based on assumptions similar to those illustrated in Fig. $6 \mathrm{~A}$; that each species has geometric potential growth which is influenced by many independent variables. However, the log-normal differs from this model in that it predicts a mode in the species abundance distributions. It is implicit in the use of the logarithmic scale for plotting species abundance distributions that all species have geometric, rather than an arithmetic, population growth. The model presented here suggests that for many species geometric growth is (a) either not achieved or (b) is so low as to be indistinguishable from arithmetic growth. A geometric growth potential may not be achieved, because of mortality and/or competitive exclusion, and the abundance of a potential middle or high ranking species may, by chance, be no greater than that of a species with arithmetic growth (e.g. species ' $9,10,5$ ', see above). Further, the geometric growth potential of some species is low and even if these species approach their potential they always have low abundance. If competition were less intense the horizontal axis could be extended further when eventually all maximum growth potentials would be greater than arithmetic, as is implicit in the log-normal model. In addition, some species may only have an arithmetic growth potential. These species might be transient occurrences, individual migrants on passage or species at the limits of their tolerance to one or more environmental parameters, whose recruitment may only rarely exceed mortality and emigration. While it may be reasonable to suggest that all species have geometric growth potential somewhere in their geographical range this may not be true for the location sampled. This model differs from the log-normal in that it allows a sample to contain species from that part of their population which has a potential or actual growth rate no greater than arithmetic. If this prediction is valid then the logarithmic scale is not the appropriate means for presenting species abundance distributions.

Marine benthic communities have been confirmed as truncated log-normal, despite the absence of a mode (Gage and Tett, 1973; Gray, 1978), but with tests of doubtful discriminating power (Taylor et al. 1976; Engen, 1979; Routledge, 1980). Here the presumption of log-normality perhaps reflects the widely held acceptance of its ubiquity on the grounds that there ought to be a small number of rare species because these animals have a high risk of local extinction (Routledge, 1980). A corollary of this reasoning is that samples that do not show a mode are simply small 
samples from log-normal communities (Routledge, 1980). This argument seems reasonable for large or discrete communities (e.g. islands) in which recruitment is mostly from within (births), but in communities open to invasion rare species may be maintained by immigration from centres of population elsewhere This may be particularly true in benthic marine communities because most marine invertebrates undergo obligatory, and often widespread, dispersal as pelagic eggs and/or larvae, while only a small proportion of marine invertebrates live close to their parents. It may be significant that the communities that consistently show a definite mode in their species abundance distributions are those of semi-enclosed sea-lochs (Pearson, 1975). In these benthic communities births are the most significant source of recruits, because of the containment of larvae within the lochs (Pearson, 1970), while the level of immigration is correspondingly unusually low.

\section{CONCLUSIONS}

This theory is presented as an ecologically based alternative to the resource-apportioning theories associated with the log-normal and log-series models of community structure. The model used to illustrate the theory is derived from general ecological considerations and successfully simulates several established features of benthic community dynamics as well as consistently producing species abundance spectra more like those of natural communities than either of the logarithmic models. The model does have some shortcomings, notably there is no provision for 'secondary' space (animals that are a substratum for others) which would increase the carrying capacity of the habitat. The assumption that the number of spaces occupied is the same as the number of individuals means that for colonial (modular) or large animals the conception of variable space size has to be introduced. Despite these shortcomings the model provides a general description of the dynamics of marine communities and shows that their structure may be explained by reference to ecological principles rather than by recourse to the 2 mathematical distributions previously used as a basis for an explanation, but which have previously been applied with varying degrees of accuracy and satisfaction.

\section{APPENDIX}

E was calculated from the formula

$$
E=\frac{70,000}{N_{t}+1}+0.25
$$

derived from 2 generalisations. Firstly, immigration ought to be prevented only if $N_{t}$ exceeds 120,000 (when $N_{t+1}$ was usually greater than 100,000) and in order that $E \times N_{t}=10^{5}, E=0.83$. (The proviso that $E \times N_{t}$ could not exceed $10^{5}$ was necessary.) Secondly, a value of $E$ of 2.0 at $N_{t}=40,000$ was estimated to be appropriate by reviewing the levels of recruitment without $E$ in the model. The above expression produces a linear relationship between $N$, and $E$ that satisfies both requirements. At the lowest values of $N_{t}$ E increases to unrealistic levels and the restriction that $E$ could not exceed 2.0 was added.

\section{LITERATURE CITED}

Austin, A. D., Austin, S. A., Sale, P. F. (1980). Community structure of the fauna associated with the coral Pocillopora damicornis (L.) on the Great Barrier Reef. Aust. J. mar Freshwat. Res. 31: 163-174

Ayling, A. M. (1981). The role of biological disturbance in temperate subtidal encrusting communities. Ecology 62 : $830-847$

Boswell, M. T. Patil, G. P. (1971). Chance mechanisms generating the logarithmic series distribution used in the analysis of numbers of species and individuals. In: Patil, G. P., Pielou, E. C., Waters, W. E. (ed.) Statistical ecology. Pennsylvania State University Press, Pennsylvania, p. $99-130$

Buchanan, J. B., Warwick, R. M. (1975). An estimate of benthic macrofaunal production in the offshore mud of the Northumberland coast. J. mar, biol. Ass. U. K. 54: 197-222

Campbell, J. I., Meadows, P. S. (1974). Gregarious behaviour in a marine benthic amphipod. Experientia 30: 1396

Connell, J. H. (1978). Diversity in tropical rain forests and coral reefs. Science, N. Y 199: 1302-1310

Crisp, D. J. (1976). Settlement responses in marine organisms. In: Newell, R. C. (ed.) Adaptations to environment. Essays on the physiology of marine organisms. Butterworths, London, p. 83-124

Davis, P. H., Spies, R. B. (1980). Infaunal benthos of a natural petroleum seep, study of community structure. Mar. Biol. 59: $31-41$

Dayton, P. K. (1971). Competition, disturbance and community organisation, the provision and subsequent utilisation of space in a rocky intertidal community. Ecol. Monogr. 41: 351-389

Eagle, R. A., Hardiman, P. A. (1977). Some observations on the relative abundance of species in a benthic community. In: Keegan, B. F., O'Ceidigh, P., Boaden, P. J. S. (ed.) Biology of benthic organisms. Pergamon, Oxford, p. $197-208$

Engen, S. (1979). Stochastic abundance models, with emphasis on biological communities and species diversity. Chapman and Hall, London

Fedra, K. (1977). Structural features of a North Adriatic benthic community. In: Keegan, B. F., O'Ceidigh, P., Boaden, P. J. S. (ed.) Biology of benthic organisms. Pergamon, Oxford, p. 233-246

Gage, J. (1972). Community structure of the benthos in Scottish sea-lochs. 1. Introduction and species diversity. Mar. Biol. 14: 281-297

Gage, J., Tett, P. B. (1973). The use of log-normal statistics to 
describe the benthos of Lochs Etive and Creran. J. Anim. Ecol. 42: 373-382

Gray, J. S. (1978). The structure of meiofauna communities. Sarsia 64: 265-272

Gray, J.S. (1981). The ecology of marine sediments. Cambridge University Press, Cambridge

Hughes, R. G. (1979). The dispersal and dispersion of some epizoites of the hydroid Nemertesia antennina (L.). J. mar. biol. Ass. U. K. 59: 879-887

Jackson, J. B. C. (1977). Competition on marine hard substrata, the adaptive significance of solitary and colonial strategies. Am. Nat. 111: 743-767

Josefson, A. B. (1981). Persistence and structure of two deep macrobenthic communities in the Skaggerak (West coast of Sweden). J. exp. mar. Biol. Ecol. 50: 63-97

Karlson, R. (1978). Predation and space utilisation patterns in a marine epifaunal community. J. exp. mar. Biol. Ecol. 31 : 225-239

Keen, S. L., Neill, W. E. (1980). Spatial relationships and some structuring processes in benthic intertidal animal communities. J. exp. mar. Biol. Ecol. 45: 139-155

Kempton, R. A., Taylor, L. R. (1976). Models and statistics for species diversity. Nature, Lond. 262: 818-820

Lubchenco, J., Menge, B. A. (1978). Community development and persistence in a low rocky intertidal zone. Ecol. Monogr. 48: 67-94

May, R. M. (1975). Patterns of species abundance and diversity. In: Cody, M. L., Diamond, J. M. (ed.) Ecology and evolution of communities. Belknap Press, Cambridge, p. $81-120$

May, R. M. (1981). Patterns in multispecies communities. In: May, R. M. (ed.) Theoretical ecology. Principles and applications. Blackwell, Oxford, p. 197-227

Meadows, P. S., Campbell, J. I. (1972). Habitat selection by aquatic invertebrates. Adv. mar Biol. 10: 271-382

Moore, P. G. (1973). The kelp fauna of Northeast Britain. 2. Multivariate classification, turbidity as an ecological factor. J. exp. mar. Biol. Ecol. 13: 127-163

Moran, P. J. (1980). Natural physical disturbance and predation, their importance in structuring a marine sessile community. Aust. J. Ecol. 5: 193-200

Osman, R. W. (1977). The establishment and development of a marine epifaunal community. Ecol. Monogr. 47: 37-63

Pearson, T. H. (1970). The benthic ecology of Loch Linnhe and
Loch Eil, a sea-loch system on the west coast of Scotland. 1. The physical environment and distribution of the macrobenthic fauna. J. exp. mar. Biol. Ecol. 5: 1-34

Pearson, T. H. (1975). The benthic ecology of Loch Linnhe and Loch Eil, a sea-loch system on the west coast of Scotland. IV Changes in the benthic fauna attributable to organic enrichment. J. exp. mar Biol. Ecol. 20:1-41

Pielou, E. C. (1975). Ecological diversity. Wiley-Interscience, New York

Preston, F. W (1948). The commoness and rarity of species. Ecology 29: 254-283

Probert, P. K. (1981). Changes in the benthic community of china clay waste deposits in Mevagissey Bay following a reduction in discharge. J. mar. biol. Ass. U. K. 61: 789-804

Rosenberg, R. (1974). Spatial dispersion of an estuarine benthic faunal community. J. exp. mar. Biol. Ecol. 15: $69-80$

Routledge, R. D. (1980). The form of species abundance distributions. J. theor. Biol. 82: 547-558

Russ, G. R. (1980). Effects of predation by fishes, competition, and structural complexity of the substratum on the establishment of a marine epifaunal community. J. exp. mar. Biol. Ecol. 42: 55-69

Shaw, K. M., Lambshead, P. J. D., Platt, H. M. (1983). Detection of pollution-induced disturbance in marine benthic assemblages with special reference to nematodes. Mar. Ecol. Prog. Ser. 11: 195-202

Simberloff, D. S., Wilson, E. O. (1969). Experimental zoogeography of islands. The colonisation of empty islands. Ecology 50: 278-296

Stoner, A. W. (1980). Perception and choise of substratum by epifaunal animals associated with seagrasses. Mar. Ecol. Prog. Ser 3: 105-111

Sutherland, J. P. (1974). Multiple stable points in natural communities. Am. Nat. 108: 859-873

Sutherland, J. P., Karlson, R. H. (1977). Development and stability of the fouling community at Beaufort, North Carolina. Ecol. Monogr. 47: 425-446

Taylor, L. R., Kempton, R. A., Woiwod, I. P. (1976). Diversity statistics and the log-series model. J. Anim. Ecol. 45: 255-272

Ugland, K. I., Gray, J. S. (1982). Log-normal distributions and the concept of community equilibrium. Oikos 39: 171-178 